\title{
What Harm Does a Second Delivery to the Pelvic Floor?
}

\author{
K. Jundt ${ }^{1}$, I. Scheer ${ }^{2}$, V. von Bodungen ${ }^{1}$, F. Krumbachner ${ }^{1}$, K. Friese $^{1}$, U. M. Peschers ${ }^{3}$ \\ ${ }^{1}$ I. Department of Obstetrics and Gynecology, Beckenbodenzentrum der LMU, Ludwig-Maximilians-Universitaet, Munich, Germany, \\ ${ }^{2}$ Department Gynäkologie, Spitalzentrum Oberwallis, Visp, Swiss, \\ ${ }^{3}$ Beckenboden Zentrum München, Chirurgische Klinik München-Bogenhausen, Munich, Germany
}

\begin{abstract}
Objective: To compare the pelvic floor function of primiparous women to women after a second delivery regarding symptoms of urinary and anal incontinence, anal sphincter ruptures and bladder-neck mobility.

Methods: A questionnaire evaluating symptoms of urinary and anal incontinence was used in nulliparous women before and 27 months after childbirth. Furthermore these symptoms were correlated with functional changes of the pelvic floor based on a careful gynecologic examination as well as perineal and endoanal ultrasound.

Results: 112 nulliparous women were included, 49 women returned for follow-up on average 27 months (SD 4.4 months) after the first delivery. 39 women (group A) had just one delivery, 10 women (group B 10/49) had had a second delivery. Apart from levator ani muscle strength, no significant difference between pelvic floor function of group A vs group B was demonstrable. Furthermore, we could show no significant difference for symptoms of urinary (11 (28.2\%) vs. $5(50.0 \%)$ ) and anal incontinence $(14(35.9 \%)$ vs. 4 $(40.0 \%))$ between both groups. However, we found a lasting increase of stress urinary and anal incontinence as well as overactive bladder symptoms after one or more deliveries. The position of the bladder neck at rest was lower in both groups compared to the position before the first delivery and bladder neck mobility increased after one or more deliveries.

Discussion: Our study shows several statistically significant changes of the pelvic floor function even on average 27 months after delivery, but a subsequent delivery did not compromise the pelvic floor any further.
\end{abstract}

Key-words: second delivery, pelvic floor, urinary incontinence, anal incontinence, levator ani muscle

Abbreviations: SUI - stress urinary incontinence, ICS - International Continence Society, OAB - overactive bladder, LAM - levator ani muscle, Introduction

\section{INTRODUCTION}

Urinary and fecal incontinence as well as genital prolapse in women are problems that frequently occur after childbirth.

Women with the onset of stress urinary incontinence during their first pregnancy or puerperal period have an increased risk of long-lasting symptoms. Viktrup and co-workers showed that twelve years after their first delivery the prevalence of stress urinary incontinence is $42 \%$ (102 of 241) and that the prevalence of SUI among women with onset during their first pregnancy $(56 \%)$ and among women with onset shortly after delivery $(78 \%)$ is significantly higher compared to those without initial symptoms (30\%) (Viktrup et al. 2006).

The Norwegian EPINCONT Study showed that the risk of urinary incontinence is higher among women who have had cesarean-sections than among nulliparous women and is even higher among women who have had vaginal deliveries (Rortveit et al. 2003). Furthermore this study could demonstrate that being older than 25 years at the first delivery is associated with incontinence and that this effect attenuates with increasing age (Rortveit et al. 2003).

The prevalence of anal incontinence among primiparous women after childbirth ranges from $4 \%-32 \%$ depending on the definition and the test methods used (Baydock et al. 2009, Hatem et al. 2005, Pollack et al. 2004).

Injury to the anal sphincter may occur from direct injury to the muscles or neurological damage (Yilmaz et al. 2008, Sultan et al. 1993, Snooks et al. 1984, Deen et al. 1993, Allen et al. 1990). Direct injury to the muscles is usually a complication of a woman's first delivery (Sultan et al. 1993) and damage to the nerves persists usually and may worsen with time (Snooks et al 1990). The pressure applied by the enlarged uterus and fetus can damage the nerves in the pubococcygeus muscle and external anal sphincter and cause fecal incontinence (Snooks et al. 1986).

While there are several studies evaluating the effect of the first delivery on pelvic floor function we have little knowledge about the effect of a second birth.

So the aim of our study was to evaluate the symptoms of incontinence and the function of the pelvic floor in women on average 27 months after their first delivery and compare women with and without a second delivery in between.

\section{PATIENTS AND Methods}

The study was undertaken in a Munich University hospital with more than 2000 deliveries per year. The study protocol was approved by the local Ethics Com- 
mittee. Nulliparous women were recruited from the antenatal clinics. Included were those who were more than 32 weeks pregnant, had a singleton pregnancy, were 18 years or older and were able to give informed consent. Exclusion criteria were complicated pregnancies (e.g. multiple pregnancy, macrosomia, fetal growth restriction, fetal malformations, hydramnion, oligohydramnion), women with perineal or vaginal operation in past medical history, preterm rupture of membranes at the time of examination, age less than 18 years, and inability to communicate with care providers due to language difficulties.

Between April 2002 and May 2003112 women were included in our prospective observational cohort study. After written informed consent, women were invited to an appointment to the urogynecological department. At the first visit between the $32^{\text {nd }}$ and $37^{\text {th }}$ gestational week and at the following visits 6 months and on average 27 months after childbirth, women were asked to complete a detailed non-validated questionnaire concerning the symptoms of urinary and anal incontinence. This questionnaire assessed the frequency of symptoms (once a month, once a week, several times a week, daily, several times daily) and whether these problems occurred for the first time before or during pregnancy (evaluated at first visit) or after childbirth (evaluated at follow-up visit). To measure the impact on quality of life, a visual analog score was also completed. A pelvic examination was then performed in the lithotomy position. Genital descent was measured at rest and straining, using the POP-Q grading system proposed by the International Continence Society (Bump et al. 1996). The length of the vaginal introitus and the perineum were evaluated and women were instructed on the technique of pelvic floor muscle contraction: digital palpation of pelvic muscle strength was graded according to the Oxford scoring system $(0=$ nil, $1=$ flicker, 2 = weak, $3=$ medium, $4=$ strong, and 5 = very strong). (Laycock 1995).

Perineal ultrasound was performed using a 7.5$\mathrm{MHz}$ probe to objectively measure the bladder neck mobility. The bladder neck was visualized in relation to the pubis. An initial scan was performed at rest and at valsalva (excursion). Maximum excursion of the bladder neck during valsalva was encouraged by asking the subjects to press while watching their own bladder neck movement on a monitor showing the real-time ultrasound image. A similar method was employed to evaluate maximum bladder neck elevation by imaging the bladder neck while asking the patient to perform a maximum pelvic floor squeeze. A x-y coordinate system was used to analyze the bladder neck mobility (Schaer et al. 1995) A reference line was drawn through the axis of the pubic symphysis (x-axis). A second line was then drawn perpendicular to this to intersect at the inferoposterior margin of the symphysis pubis (y-axis). The position of the bladder neck during rest, valsalva, and pelvic floor squeeze could thus be defined by these two coordinates. The bladder neck mobility was measured in $[\mathrm{cm}]$ as the length of the vector between the position of the bladder neck at rest and with valsalva.

Endoanal ultrasound was performed using a 10 $\mathrm{MHz}$ rotating probe (B\&K Medical, Naerum, Denmark). The technique has been previously described: static images were recorded at four levels (puborectalis, deep, superficial and subcutaneous external sphincter) (Sultan et al. 1994). To avoid over-reporting, sphincter defects were considered only if they involved two levels and if both reviewers had identified the defect. Anal sphincter defects were classified into internal, external and combined.

SPSS for Windows Version 15.0 was used for statistical evaluation. $\mathrm{P}<0.05$ was defined as significant. Ttest and $\chi^{2}$-test were used as appropriate.

\section{RESULTS}

112 women were included in our study and came for the first visit, 49 women returned for follow-up on average 27 months (SD 4.4 months) after the first childbirth. 63 women were lost for follow-up (moved
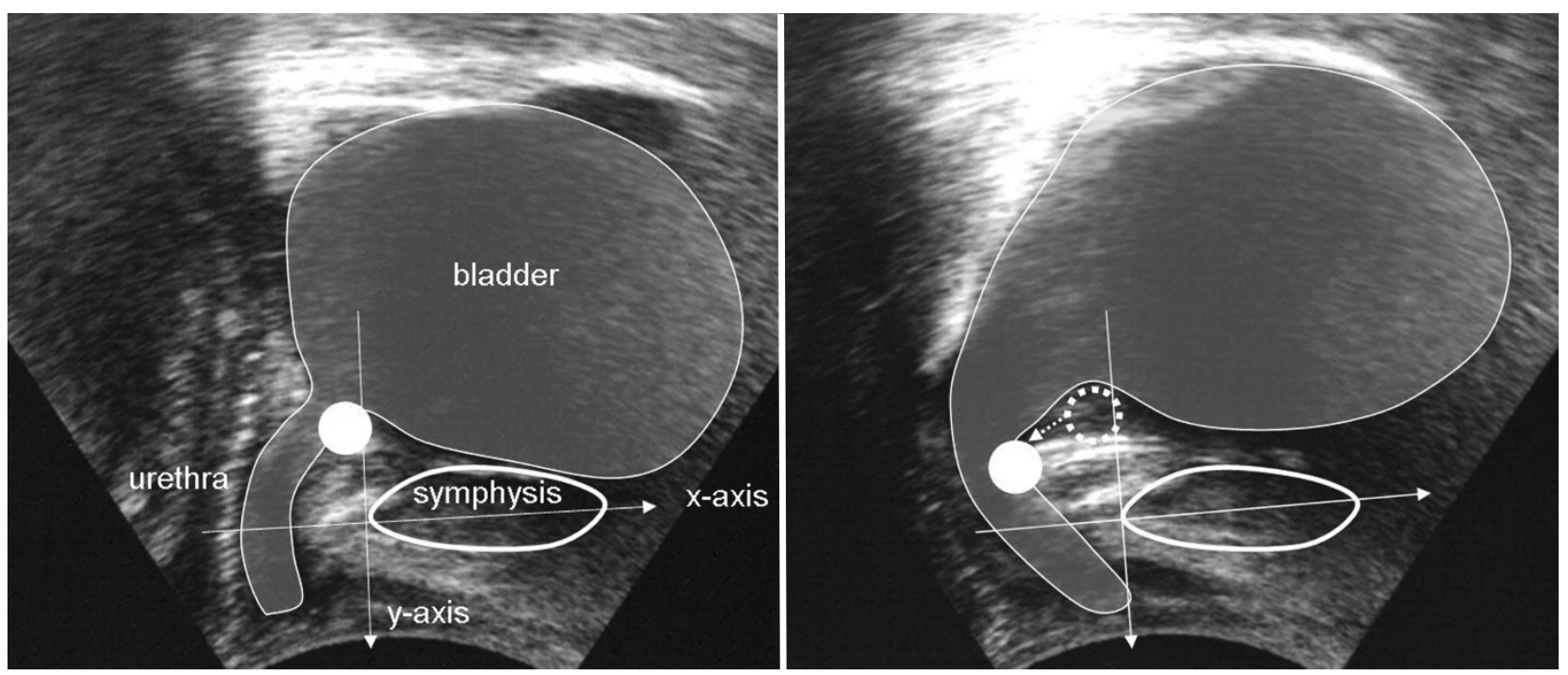

Fig. 1a, b. Perineal ultrasound for evaluating the bladder neck mobility. Bladder neck at rest (Fig. 1a) and with valsalva (Fig 1b), point indicates the bladder neck, arrow as vector for the bladder neck mobility. 
Table 1. Urinary and anal incontinence before $1^{\text {st }}$ pregnancy and 27 months after childbirth.

\begin{tabular}{lllllll}
\hline & $\begin{array}{l}\text { before } \\
1^{\text {st }} \\
(\mathrm{n}=49)\end{array}$ & $\begin{array}{l}\text { Group A } \\
(\mathrm{n}=39)\end{array}$ & $\begin{array}{l}\text { p-value } \\
\text { before } 1^{\text {st }} \\
\text { pregnancy } \\
\text { vs. A }\end{array}$ & $\begin{array}{l}\text { Group B } \\
(\mathrm{n}=10)\end{array}$ & $\begin{array}{l}\text { p-value } \\
\text { before } 1^{\text {st }} \\
\text { pregnancy } \\
\text { vs. B }\end{array}$ & $\begin{array}{l}\text { p-value } \\
\text { A vs. B }\end{array}$ \\
\hline SUI & $0(0.0 \%)$ & $\mathbf{1 1 ( 2 8 . 2 \% )}$ & $\mathbf{0 . 0 0 0 3 *}$ & $\mathbf{5 ( 5 0 . 0 \% )}$ & $\mathbf{0 . 0 0 0 1 +}^{+}$ & 0.35 \\
OAB & $0(0.0 \%)$ & $\mathbf{1 2 ( 3 0 . 8 \% )}$ & $\mathbf{0 . 0 0 0 1 *}$ & $\mathbf{3 ( 3 0 . 0 \% )}$ & $\mathbf{0 . 0 0 2}^{+}$ & 0.74 \\
$\begin{array}{l}\text { Anal } \\
\text { incontinence }\end{array}$ & $7(14.3 \%)$ & $\mathbf{1 4}(\mathbf{3 5 . 9 \% )}$ & $\mathbf{0 . 0 3 *}$ & $\mathbf{4 ( 4 0 . 0 \% )}$ & $\mathbf{0 . 0 1 4}^{+}$ & 0.89 \\
\hline
\end{tabular}

SUI - Stress Urinary Incontinence, OAB - Overactive Bladder, $* \chi^{2}$ significant with $\mathrm{p}<.05$, before 1 st pregnancy vs. $27 \mathrm{months}$ after childbirth (group A: without second delivery); ${ }^{+} \chi^{2}$ significant with $\mathrm{p}<.05$, before $1{ }^{\text {st }}$ pregnancy vs. 27 months after childbirth (group B: with second delivery)

Table 2. Quantitative parameters assessed during $1^{\text {st }}$ pregnancy and 27 months after childbirth.

\begin{tabular}{|c|c|c|c|c|c|c|}
\hline & $\begin{array}{l}\text { before } \\
1^{\text {st }} \text { pregnancy } \\
(\mathrm{n}=49)\end{array}$ & $\begin{array}{l}\text { Group A } \\
(\mathrm{n}=39)\end{array}$ & $\begin{array}{l}\text { p-value } \\
\text { before } 1^{\text {st }} \\
\text { pregnancy } \\
\text { vs. A }\end{array}$ & $\begin{array}{l}\text { Group B } \\
(\mathrm{n}=10)\end{array}$ & $\begin{array}{l}\text { p-value } \\
\text { before } 1^{\text {st }} \\
\text { pregnancy } \\
\text { vs. B }\end{array}$ & $\begin{array}{l}\text { p-value } \\
\text { A vs. B }\end{array}$ \\
\hline $\begin{array}{l}\text { LAM contraction } \\
\text { (Oxford score } 0-5)\end{array}$ & $2.6(1.15)$ & $2.97(1.12)$ & 0.131 & $2.1(1.30)$ & 0.232 & $0.039^{+}$ \\
\hline $\begin{array}{l}\text { Length of introitus } \\
(\mathrm{cm})\end{array}$ & $2.86(0.55)$ & $2.83(0.64)$ & 0.813 & $2.89(0.67)$ & 0.878 & 0.794 \\
\hline $\begin{array}{l}\text { Length of perineum } \\
(\mathrm{cm})\end{array}$ & $3.81(0.87)$ & $2.83(0.60)$ & $<0.0001^{*}$ & $2.98(0.57)$ & $0.006 *$ & 0.48 \\
\hline $\begin{array}{l}\text { Thickness M. } \\
\text { sphincter ani ext. (cm) }\end{array}$ & $0.83(0.17)$ & $0.78(0.15)$ & 0.152 & $0.79(0.16)$ & 0.496 & 0.144 \\
\hline $\begin{array}{l}\text { Thickness M. } \\
\text { sphincter ani int. }(\mathrm{cm})\end{array}$ & $0.19(0.06)$ & $0.19(0.08)$ & 1 & $0.22(0.07)$ & 0.166 & 0.285 \\
\hline
\end{tabular}

LAM - Levator ani muscle, * t-test significant with $\mathrm{p}<.05$, during pregnancy vs. 27 months after childbirth (group A: without second delivery / group B: with second delivery), ${ }^{+} \mathrm{t}$-test significant with $\mathrm{p}<.05$, group A vs. group B

somewhere else and could not be reached by mail or phone or declined to participate). The mean age of these women was 35.2 (SD 4.0) years at the follow-up visit.

We divided our patients in two groups: group A 39 of the 49 women $(79.6 \%)$ had just one delivery (24 $(61.5 \%)$ spontaneous vaginal delivery, $9(23.1 \%)$ a vacuum extraction, $6(15.4 \%)$ had a cesarean section), group B - 10 women $(20.4 \%)$ had a second delivery (on average 7.9 months after $2^{\text {nd }}$ delivery) (7 (70.0\%) a spontaneous vaginal delivery, $3(30.0 \%)$ a cesarean section). All women with c-section at the second delivery had an elective cesarean-section.

The average weight for the first child was $3326 \mathrm{~g}$ (2220-4300 g), the average weight for the second child was $3506 \mathrm{~g}(2700-4180 \mathrm{~g})$. At the first delivery: 7 women $(14.3 \%)$ had a midline and $9(18.4 \%)$ had a mediolateral episiotomy. 4 times $(8.2 \%)$ a $\mathrm{I}^{\circ}$ perineal tear occurred, 7 times $(14.3 \%)$ a $\mathrm{II}^{\circ}$ and 2 times (4.1\%) a $\mathrm{III}^{\circ}$ tear with rupture of the anal sphincter. At the second delivery, no episiotomy was performed and twice a $\mathrm{I}^{\circ}$ perineal tear occurred and once a $\mathrm{II}^{\circ}$ and $\mathrm{III}^{\circ}$ tear (this was a women with $4180 \mathrm{~g}$ child weight and already a $\mathrm{III}^{\circ}$ tear during the first delivery).

The results of the questionnaire concerning urinary and anal incontinence are presented in Table 1.
The differences in pelvic floor function before and after childbirth are presented in Table 2. No women showed a vaginal prolapse of more than stage 2 according to the POP-Q-system.

Endoanal ultrasound showed no sphincter laceration before childbirth; after delivery $(n=49)$ four $(8.1 \%)$ occult sphincter defects in addition to two known sphincter ruptures could be demonstrated. Only two of those six women reported flatus incontinence post partum. Therefore there appears to be no correlation between sphincter lesions and the presence of symptoms of anal incontinence after childbirth.

Perineal ultrasound showed no significant difference between the position of the bladder neck at rest before and after delivery. We could show a significant increase in bladder neck mobility between the status during the first pregnancy and after one (group A) or two (group B) deliveries, but the increase in bladder neck mobility between group A vs. B was not significant. (Table 3)

\section{DisCusSION}

Our study shows that there was - apart from the levator ani muscle contraction - no significant difference between the pelvic floor function of women with one 
Table 3. Bladder neck mobility during $1^{\text {st }}$ pregnancy and 27 months after childbirth.

\begin{tabular}{|c|c|c|c|c|}
\hline & \multicolumn{2}{|c|}{$\begin{array}{l}\text { Bladder neck mobility } \\
\text { Mean (SD) }[\mathrm{cm}]\end{array}$} & \multirow{2}{*}{$\begin{array}{c}\text { p-value* } \\
\text { during } 1^{\text {st }} \text { pregnancy, } \\
\text { vs. } 27 \text { months after } \\
\text { delivery }\end{array}$} & \multirow{2}{*}{$\begin{array}{c}\text { p-value* } \\
\text { group A } \\
\text { vs. group B }\end{array}$} \\
\hline & $\begin{array}{l}\text { during } 1^{\text {st }} \\
\text { pregnancy }\end{array}$ & $\begin{array}{l}27 \text { months } \\
\text { after childbirth }\end{array}$ & & \\
\hline group A $(n=39)$ & $1.27(.77)$ & $1.74(.77)$ & 0.0086 & \multirow{2}{*}{.311} \\
\hline $\operatorname{group} B(\mathrm{n}=10)$ & $1.13(.75)$ & $2.03(.85)$ & .032 & \\
\hline
\end{tabular}

SD - standard deviation, group A - without second delivery, group B - with second delivery, ${ }^{*}$ t-test comparison; bold numbers: significant difference with $\mathrm{p}<.05$

or two childbirths. Furthermore the symptoms for urinary and anal incontinence differed not significantly between both of our groups. However, we could demonstrate a lasting increase of the prevalence of stress urinary and anal incontinence as well as overactive bladder symptoms after one or more deliveries. The position of the bladder neck at rest decreased in both of our groups without any significant differences between the groups.

To our knowledge, this is the first study evaluating the pelvic floor of women after just one delivery compared to women with a subsequent delivery, including and examining them during the first and the subsequent pregnancy. We could only find data regarding faecal continence. One study by Fynes et al examined women only after their first delivery. If they showed transient faecal incontinence or occult anal-sphincter injury after their first vaginal delivery they were at high risk of faecal incontinence after a second vaginal delivery. They also concluded that the risk of mechanical anal sphincter injury was greatest after the first delivery (Fynes et al. 1999). A further study by Scheer et al. recommended that women who have no antenatal evidence of objective compromise of anal sphincter function after previous obstetric anal sphincter injuries can be reassured that a vaginal delivery is not associated with any significant deterioration in function or quality of life.

The significant increase of stress urinary and anal incontinence symptoms and $\mathrm{OAB}$ in both groups was also demonstrable in our earlier published data on these 112 women. (Jundt et al. 2010) 6 months after first delivery stress and flatus incontinence significantly increased after spontaneous delivery or vacuum extraction. No new symptoms occurred after c-section. This is in accordance to Rortveit et al who questioned 15307 Norwegian women about stress urinary incontinence. They could show that the risk of urinary incontinence is higher among women who have had cesarean sections than among nulliparous women and is even higher among women who have had vaginal deliveries (Rortveit et al. 2006)

Therefore, the risk to develop symptoms of urinary and anal incontinence seems to increase with the first delivery, but seems to stay the same after the second. As there are only 49 women left to follow up, we were not able to divide them according to their mode of delivery.

This is in agreement with Bahl et al. who evaluated 283 women for pelvic floor morbidity at 3 years after instrumental delivery and cesarean delivery in the sec- ond stage of labor using just postal questionnaires. They stated that pelvic floor symptoms were not exacerbated by a subsequent delivery (Bahl et al. 2005).

On the contrary, Faltin and co-workers who examined 100 women 3 months and 30 months after their first delivery conclude that subsequent deliveries increase the risk of anal incontinence, particularly among women with a sphincter defect diagnosed after the first delivery (Faltin et al. 2001].

As our data suggest that the bladder neck position changes by the first delivery, we could not find any data in literature about the change of the bladder neck position at rest and the bladder neck mobility after a subsequent delivery.

One woman with $\mathrm{III}^{\circ}$ perineal tear during their first delivery sustained another $\mathrm{III}^{\circ}$ tear during her second delivery. Obviously, the scar tissue after sphincter laceration is at high risk to tear again during a second delivery. An elective c-section could have avoided another sphincter rupture and McKenna furthermore states that elective c-section after sphincter rupture will prevent most cases of anal incontinence, although marginally increasing maternal risk, which may be justified by the potential benefits (McKenna et al. 2003).

A limitation of our study is the small number of women who returned for follow-up. This includes the bias that maybe only these women with complaints come back and furthermore makes it difficult to draw statistically significant conclusions.

The time period was short for follow up, but a longer interval bears the risk that even more women could have moved away.

In conclusion our study showed that there are statistically significant changes of the pelvic floor even on average 27 months after delivery, but a subsequent delivery did not compromise the pelvic floor any further.

\section{REFERENCES}

1. Allen RE, Hosker GL, Smith ARB, Warren DW. Pelvic floor damage and childbirth: a neurophysiological study. Br J Obstet Gynaecol 1990;97(9):770-9.

2. Bahl R, Strachan B, Murphy DJ. Pelvic floor morbidity at 3 years after instrumental delivery and cesarean delivery in the second stage of labor and the impact of a subsequent delivery. Am J Obstet Gynecol. 2005 Mar;192(3): 789-94.

3. Baydock SA, Flood C, Schulz JA, MacDonald D, Esau D, Jones S, Hiltz CB. Prevalence and risk factors for urinary and fecal incontinence four months after vaginal delivery. J Obstet Gynaecol Can. 2009 Jan;31(1):36-41. 
4. Bump RC, Mattiasson A, Bø K, et al. The standardization of terminology of female pelvic organ prolapse and pelvic floor dysfunction. Am J Obstet Gynecol. 1996 Jul;175(1): 10-7.

5. Deen KI, Kumar D, Williams JG, Olliff J, Keighley MR. The prevalence of anal sphincter defects in faecal incontinence: a prospective endosonic study. Gut 1993;34(5): 685-8.

6. Faltin DL, Sangalli MR, Roche B, Floris L, Boulvain M, Weil A. Does a second delivery increase the risk of anal incontinence? BJOG. $2001 \mathrm{Jul} ; 108(7): 684-8$.

7. Fynes M, Donnelly V, Behan M, O'Connell PR, O'Herlihy $\mathrm{C}$. Effect of second vaginal delivery on anorectal physiology and faecal continence: a prospective study. Lancet. 1999 Sep 18;354(9183):983-6.

8. Hatem M, Fraser W, Lepire E. Postpartum urinary and anal incontinence: a population-based study of quality of life of primiparous women in Quebec. J Obstet Gynaecol Can. 2005 Jul;27(7):682-8.

9. Jundt K, Scheer I, Schiessl B, Karl K, Friese K, Peschers UM. Incontinence bladder neck mobility, and sphincter ruptures in primiparous women. EurJMedRes 2010, accepted for publication.

10. Laycock J. Pelvic Floor Dysfunction, Ph.D. Thesis. Bradford University; 1995.

11. McKenna DS, Ester JB, Fischer JR. Elective cesarean delivery for women with a previous anal sphincter rupture. Am J Obstet Gynecol. 2003 Nov;189(5):1251-6.

12. Pollack J, Nordenstam J, Brismar S, Lopez A, Altman D, Zetterstrom J. Anal incontinence after vaginal delivery: a five-year prospective cohort study. Obstet Gynecol. 2004 Dec;104(6):1397-402.

13. Rortveit G, Daltveit AK, Hannestad YS, Hunskaar S; Norwegian EPINCONT Study. Urinary incontinence after vaginal delivery or cesarean section. N Engl J Med. 2003 Mar 6;348(10):900-7.

14. Rortveit G, Hunskaar S. Urinary incontinence and age at the first and last delivery: the Norwegian HUNT/EPINCONT study. Am J Obstet Gynecol. 2006 Aug;195(2): 433-8. Epub 2006 Apr 21.

15. Schaer GN, Koechli OR, Schuessler B, Haller U. Perineal ultrasound for evaluating the bladder neck in urinary stress incontinence. Obstet Gynecol 1995; 85(220):224.
16. Scheer I, Thakar R, Sultan AH. Mode of delivery after (OASIS)--a reappraisal? Int Urogynecol J Pelvic Floor Dysfunct. 2009 Sep;20(9):1095-101.

17. Snooks SJ, Swash M, Henry MM, Setchell M. Risk factors in childbirth causing damage to the pelvic nerve innervation. Int J Colorectal Dis 1986;1(1):20-4.

18. Snooks SJ, Swash M, Mathers SE, Henry MM. Effect of vaginal delivery on the pelvic floor: a 5 -year follow-up. $\mathrm{Br}$ J Surg 1990;77(12):1358-60.

19. Snooks SJ, Swash M, Setchell M, Henry MM. Injury to innervation of pelvic floor sphincter musculature in childbirth. Lancet 1984;2(8402):546-50.

20. Sultan AH, Kamm MA, Hudson CN, Bartram C. Analsphincter disruption during vaginal delivery. N Engl J Med 1993;329(26): 1905-11.

21. Sultan AH, Kamm MA, Hudson CN, Nicholls JR, Bartram CI. Endosonography of the anal sphincters: normal anatomy and comparison with manometry. Clin Radiol 1994:49:368-74.

22. Viktrup L, Rortveit G, Lose G. Risk of stress urinary incontinence twelve years after the first pregnancy and delivery. Obstet Gynecol. 2006 Aug;108(2):248-54.

23. Yilmaz E, Nas T, Korucuoglu U, Guler I. Manometric evaluation of anal sphincter function after vaginal and cesarean delivery. Int J Gynaecol Obstet. 2008 Nov;103(2): 162-5. Epub 2008 Aug 21.

Received: February 20, 2010 / Accepted: May 12, 2010

Address for correspondence:

Katharina Jundt, M.D.

Department of Gynecology and Obstetrics -

Campus Innenstadt

Ludwig-Maximilians-University

Maistr. 11

80337 München

Germany

Phone: +49-89-5160-4111

Fax: $\quad+49-89-5160-4166$

E-mail: katharina.jundt@med.uni-muenchen.de 